\title{
Sensitivity Analysis of Coupled Crowd-structure System dynamics to Walking Crowd Properties
}

\author{
E. Shahabpoor \\ Doctoral researcher, Department of Civil \& Structural Engineering, University of Sheffield, UK
}

A. Pavic

Professor of Vibration Engineering, College of Engineering, Mathematics and Physical Sciences, University of Exeter, UK

V. Racic

Lecturer, Department of Civil \& Structural Engineering, University of Sheffield, UK

ABSTRACT: Increasing vibration serviceability problems of modern structures have drawn researchers' attention to the walking-induced vibration modelling and assessment of floors and footbridges. Changes of dynamic properties of structure due to presence of stationary people have been studied extensively in the literature. However, little is known about the similar effects of walking people, mainly due to the lack of experimental evidence and credible models capable of simulating human-structure dynamic interaction (HSI) in the vertical direction. This paper uses a single degree of freedom mass-spring-damper (MSD) model to simulate dynamics of walking crowd ${ }^{1}$ on structure and investigates the sensitivity of the coupled crowdstructure system frequency and damping to properties of crowd model. Results of this study show that when the natural frequency of the crowd model is less than the natural frequency of the structure, both natural frequency and damping ratio of occupied structure are more sensitive to crowd's model stiffness. Similarly, when the natural frequency of the crowd model is greater than the natural frequency of the structure, both natural frequency and damping ratio of occupied structure are more sensitive to crowd's model mass. It also can be seen that natural frequency of the occupied structure has no sensitivity to damping of the crowd model while its damping ratio shows a limited sensitivity to the crowd's model damping with the maximum where both natural frequencies are equal.

\section{INTRODUCTION}

Recent increase in vibration serviceability problems of flexible structures under human dynamic loading have led to concerns about both safety and comfort of pedestrians using such structures. Hence, there is demand for more accurate and inclusive design methods (Shahabpoor \& Pavic 2012, Zivanovic et al. 2010, Kasperski 1996, Reid et al. 1997, SCOSS 2001). As to the walking-induced dynamic loading, current design approaches, such as those in BS 5400 (2006) and Eurocode 5 (2004), use deterministic walking force models and simply ignore humanstructure interaction effects and inherent stochasticity of the walking force (Shahabpoor \& Pavic 2012, Zivanovic et al. 2010, Dougill 2006). Research (Shahabpoor \& Pavic 2012, Zivanovic et al. 2010, Ellis \& Ji 1997, Willford 2002, Brownjohn et al. 2004, Pavic 2011), mostly based on full-scale measurements, have indicated that interaction of the human body, as a bio-mechanical system, with the structure have significant effects on dynamic

\footnotetext{
${ }^{1}$ In this paper, 'crowd' is called to any group of people with more than a single person.
}

properties of the joint human-structure system and should be considered. It often leads to a considerable reduction in response and some change in the natural frequency of the structure (Shahabpoor \& Pavic 2012, Zivanovic et al. 2010, Dougill 2006, Pavic 2011).

To address HSI, different types of mechanical or biomechanically-inspired models, such as single/ multiple degrees of freedom mass-spring dampers MSDs (Archbold 2004, 2008, 2011, Caprani et al. 2011) and single/bipedal inverted pendulum (Bocian 2011), are used to simulate kinematics of human motion for both vertical and horizontal directions and different postures and types of activities (Macdonald 2009, Matsumoto \& Griffin 2003, Wei $\&$ Griffin 1998). This paper uses a classic single degree of freedom mass-spring-damper (S-MSD) model to simulate crowd-structure interaction during walking by using human body MSD properties. Although this S-MSD model may not be the best option for modeling human, the simplicity of its dynamics allows easy investigation of highly relevant coupled human-structure system dynamics under different loading conditions. The principal aim of this study is to improve understanding of the 
sensitivity of the occupied structure dynamic properties to each of the currently uncertain crowd parameters. This is done for a range of common structures and crowd occupation scenarios and should help dealing with large uncertainty when modeling crowds on structures during design process.

Section 1 of the paper presents a very short introduction into the subject and rationale of this research. Section 2 describes the proposed coupled S-MSD model and its formulation for the considered crowd occupation scenarios. Section 3 presents the analysis specifications and Section 4 illustrates the parameters used in the models. Section 5 presents the results of the parametric study and sensitivity analysis and finally Section 6 closes the paper by highlighting the important findings and making conclusions.

\section{S-MSD MODEL DESCRIPTION}

To simulate the problem, only the first mode of structural vibration is considered and is conceptualized using a SDOF oscillator with the corresponding modal properties $\left(\mathrm{m}_{\mathrm{s}}, \mathrm{k}_{\mathrm{s}}\right.$ and $\left.\mathrm{c}_{\mathrm{s}}\right)$. Considering only one structural mode does not affect the generality of the results as mode superposition principle applies to linear structures which is an acceptable assumption for this kind of problem.

In all simulations, a S-MSD model $\left(\mathrm{m}_{\mathrm{c}}, \mathrm{k}_{\mathrm{c}}\right.$ and $\left.\mathrm{c}_{\mathrm{c}}\right)$ is used to simulate the effects of the crowd's MSD properties on the structure. This model represents 'stationary' walking pedestrian -an imaginary case in which people are 'walking' on the 'anti-node' of the first mode of vibration but their location on the structure does not change ${ }^{2}$. Being stationary, such coupled crowd-structure system can be represented as a simple conventional two degrees of freedom system as illustrated in Figure 1, the behavior of which can be studied using closed form solutions of 2DOF equations of motion.

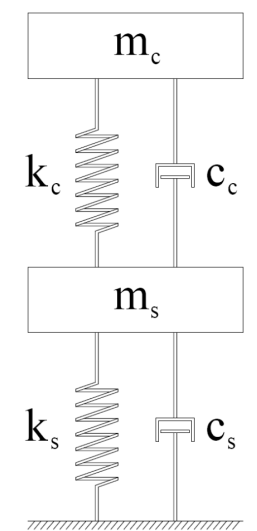

Figure 1. Conceptual 2DOF model of coupled crowd-structure system (stationary walking people)

\footnotetext{
2 e.g. assume walking on a series of treadmills distributed over
} the length of a beam-like structure
More detailed discussion about the selected 2DOFs crowd-structure model and its equations of motion are presented by Shahabpoor et al. (2013).

\section{ANALYSIS SPECIFICATIONS}

The natural frequency $f_{\text {os }}$ and damping ratio $\zeta_{\text {os }}$ of the occupied structure are chosen to represent dynamics of the occupied structure. In the first step, crowd's properties $\left(\mathrm{m}_{\mathrm{c}}, \mathrm{k}_{\mathrm{c}}\right.$ and $\left.\mathrm{c}_{\mathrm{c}}\right)$ are changed one at a time and the effect of this single parameter on natural frequency $f_{o s}$ and damping ratio $\zeta_{o s}$ of the occupied structure are calculated.

In the next step, the rates of change of $\mathrm{f}_{\mathrm{os}}$ and $\zeta_{\mathrm{os}}$ of the occupied structure with respect to change of crowd's model properties $\mathrm{m}_{\mathrm{c}}, \mathrm{k}_{\mathrm{c}}$ and $\mathrm{c}_{\mathrm{c}}$ is considered as the sensitivity criteria. The chosen rate of change provides a measure of 'how fast' the occupied structure properties $\mathrm{f}_{\mathrm{os}}$ and $\zeta_{\mathrm{os}}$ change as uncertain crowd's parameters $\mathrm{m}_{\mathrm{c}}, \mathrm{k}_{\mathrm{c}}$ and $\mathrm{c}_{\mathrm{c}}$ change.

To allow for comparison, as units of MSD parameters are different, a typical set of initial values for structure and crowd's parameters $\left(\mathrm{m}_{\mathrm{ci}}, \mathrm{c}_{\mathrm{ci}}, \mathrm{k}_{\mathrm{ci}}\right.$, $\mathrm{f}_{\mathrm{si}}$ and $\zeta_{\mathrm{si}}$, are selected and unit-less ratios $\mathrm{m}_{\mathrm{c}} / \mathrm{m}_{\mathrm{ci}}$, $\mathrm{c}_{\mathrm{c}} / \mathrm{c}_{\mathrm{ci}}, \mathrm{k}_{\mathrm{c}} / \mathrm{k}_{\mathrm{ci}}, \mathrm{f}_{\mathrm{os}} / \mathrm{f}_{\mathrm{si}}$ and $\zeta_{\mathrm{os}} / \zeta_{\mathrm{si}}$ are used for presentation. To ensure generality of results, the same analysis is repeated for several initial values and results are compared. The effects on $\mathrm{f}_{\mathrm{os}}$ and $\zeta_{\mathrm{os}}$ are considered for the changes of $\mathrm{m}_{\mathrm{c}}$ (Case 1), $\mathrm{k}_{\mathrm{c}}$ (Case 2), and $\mathrm{c}_{\mathrm{c}}$ (Case 3).

In all three cases, the selected crowd parameter is varying over a certain range and other two parameters of the crowd model are kept constant and equal to the initial set of values.

\section{MODEL PARAMETERS}

The exact parameters used in the crowd - structure $2 \mathrm{DOF}$ model are described in this section. These parameters are selected to be realistic and to cover a range of possible values (in the case of the varying parameter).

\subsection{Dynamic parameters of structure model}

The dynamic parameters of the crowd and structure models that are used in simulations are presented in Table 1 for different analysis cases. An imaginary simply supported beam is selected as the structure and its first mode properties $\mathrm{m}_{\mathrm{si}}, \mathrm{k}_{\mathrm{si}}$ and $\mathrm{c}_{\mathrm{si}}$ are selected in a way to be both realistic and corresponding to a light weight structure. The latter is needed to highlight the crowd-structure interaction effects better. Three different natural frequencies (and therefore stiffnesses for the same mass $\mathrm{m}_{\mathrm{si}}$ of $6500 \mathrm{~kg}$ ) are selected for the structure to cover the scenarios in which the natural frequency of the 
structure is lower, close to and higher than the assumed natural frequency of the crowd model.

\subsection{Dynamic properties of crowd model}

The initial parameters of the crowd model $\mathrm{m}_{\mathrm{ci}}, \mathrm{c}_{\mathrm{ci}}$ and $\mathrm{k}_{\mathrm{ci}}$ are adopted from the results of studies done by the author to simulate crowd's dynamics on a real-life test structure. An extensive set of experiments were carried out on the Sheffield laboratory test structure ( 2 meters wide and 11 meters long pre-stressed concrete beam) with the groups of 2-15 pedestrians walking on it. An S-MSD crowd model was then fitted to each test scenario and the corresponding crowd's parameters were found. Properties corresponding to a group of 6 walking people are selected as the initial values for the crowd model. A six-people group represents a normal spatially-unconstrained crowd on the assumed test structure and is a very good starting point to study the effects of varying crowd parameters.

Table 1. Dynamic parameters of human and structure models used in different analysis cases

\begin{tabular}{|c|c|c|c|c|c|}
\hline $\begin{array}{l}\text { Analysis } \\
\text { case }\end{array}$ & $\begin{array}{l}\text { Initial } \\
\text { values }\end{array}$ & Case 1 & Case 2 & Case 3 & Unit \\
\hline \multicolumn{6}{|c|}{ Structure model parameters } \\
\hline Mass & \multicolumn{4}{|c|}{6500} & $\mathrm{~kg}$ \\
\hline $\begin{array}{l}\text { Damping } \\
\text { ratio }\end{array}$ & \multicolumn{4}{|c|}{0.005} & - \\
\hline $\begin{array}{l}\text { Natural } \\
\text { frequency }\end{array}$ & \multicolumn{4}{|c|}{$2-4$} & $\mathrm{~Hz}$ \\
\hline \multicolumn{6}{|c|}{ Crowd model parameters } \\
\hline Mass & 168 & $8.4-462$ & 168 & 168 & $\mathrm{~kg}$ \\
\hline Stiffness & 61698 & 61698 & $\begin{array}{l}3085- \\
169669\end{array}$ & 61698 & $\mathrm{~N} / \mathrm{m}$ \\
\hline Damping & 1803 & 1803 & 1803 & $\begin{array}{l}90- \\
4958\end{array}$ & N.s $/ \mathrm{m}$ \\
\hline $\begin{array}{l}\text { Damping } \\
\text { ratio }\end{array}$ & 0.28 & $\begin{array}{l}1.25- \\
0.169\end{array}$ & $\begin{array}{l}0.984- \\
0.133\end{array}$ & $\begin{array}{l}0.014- \\
0.770\end{array}$ & - \\
\hline $\begin{array}{l}\text { Natural } \\
\text { frequency }\end{array}$ & 3.05 & $\begin{array}{l}13.64- \\
1.84\end{array}$ & $\begin{array}{l}0.68- \\
5.06\end{array}$ & 3.05 & $\mathrm{~Hz}$ \\
\hline
\end{tabular}

The ranges of possible crowd parameters $m_{c}, c_{c}, k_{c}$ are adopted from the values reported by researchers for individuals and groups of people (Archbold et al. 2011, Zhang et al. 2000, Rapoport et al. 2003, Bertos et al. 2005, Lee \& Farley 1998, Geyer et al. 1998) and are presented in Table 1.

\section{ANALYSIS RESULTS}

Distinction should be made between the results that are presented in Sections 5.1 and 5.2. The former provide a measure of 'how effective' crowd parameters $\mathrm{m}_{\mathrm{c}}, \mathrm{k}_{\mathrm{c}}$ and $\mathrm{c}_{\mathrm{c}}$ are on occupied structure dynamics (represented by $f_{o s}$ and $\zeta_{o s}$ ) while the latter gives a measure of the sensitivity of $f_{o s}$ and $\zeta_{o s}$ to crowd's uncertain parameters.

\subsection{Parametric analysis}

Figure 2 and Figure 3 present a typical set of results for $\mathrm{f}_{\mathrm{si}}=4 \mathrm{~Hz}$. Results of analysis Cases 1, 2 and 3 corresponding to changing crowd's $\mathrm{m}_{\mathrm{c}}, \mathrm{k}_{\mathrm{c}}$ and $\mathrm{c}_{\mathrm{c}}$ are plotted on the same graph to be able to compare them. The horizontal axis presents the ratio of the crowd parameters to their initial values ' $\mathrm{X}$ ', while the vertical axis presents the ratio of the changes in the occupied structure parameters ' $\mathrm{Y}$ '. These parameters are presented in equations 1 and 2 , respectively.

$X={ }^{x_{c}} / x_{c i} \therefore\left(x_{c}=m_{c}, c_{c}, k_{c}\right)$

$Y=y_{o s} / y_{s i} \therefore \quad\left(y_{o s}=f_{o s}, \zeta_{o s}\right)$

As the natural frequency of a SDOF is proportional to $k / m$, increase of stiffness or decrease of mass leads to the increase of the natural frequency. Keeping this in mind and knowing that $\mathrm{f}_{\mathrm{ci}}=3.05 \mathrm{~Hz}$ and $\mathrm{f}_{\mathrm{si}}=4 \mathrm{~Hz}$ in Figure 2 and Figure 3, increasing stiffness of the crowd model $\mathrm{k}_{\mathrm{c}}$ (blue trace) or

Figure 2. Effects of the $\mathrm{m}_{\mathrm{c}}, \mathrm{k}_{\mathrm{c}}$ and $\mathrm{c}_{\mathrm{c}}$ on $\mathrm{f}_{\mathrm{os}}\left(\mathrm{f}_{\mathrm{si}}=4 \mathrm{~Hz}\right)$
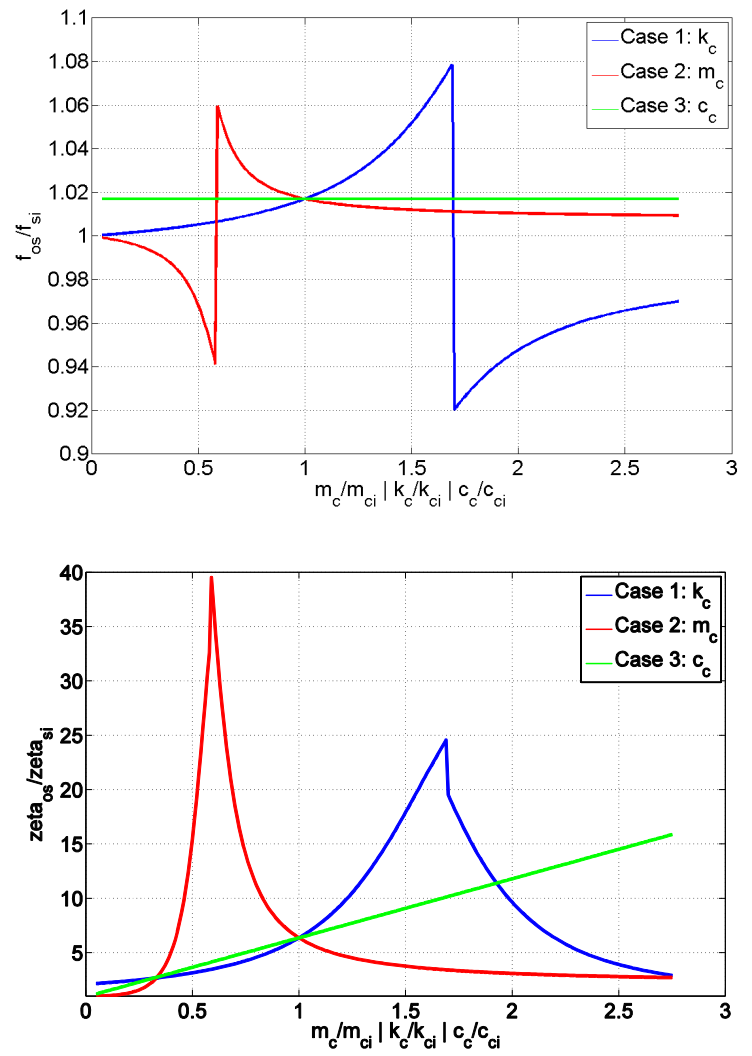

Figure 3. Effects of the $\mathrm{m}_{\mathrm{c}}, \mathrm{k}_{\mathrm{c}}$ and $\mathrm{c}_{\mathrm{c}}$ on $\zeta_{\mathrm{os}}\left(\mathrm{f}_{\mathrm{si}}=4 \mathrm{~Hz}\right)$ 
decreasing its mass $m_{c}$ (red trace) leads into an increase of the crowd's natural frequency $f_{c}$ and makes it closer to the structure's initial frequency $f_{\mathrm{si}}$.

A closer look at Figure 2 and Figure 3 shows that the extreme values of $\mathrm{m}_{\mathrm{c}}$ and $\mathrm{k}_{\mathrm{c}}$ graphs (red and blue traces) represent the cases where natural frequencies of the crowd and initial structure model are equal $\left(\mathrm{f}_{\mathrm{s}}=\mathrm{f}_{\mathrm{c}}\right)$. This means that $\mathrm{m}_{\mathrm{c}}$ and $\mathrm{k}_{\mathrm{c}}$ have maximum effects on $\mathrm{f}_{\mathrm{os}}$ and $\zeta_{\mathrm{os}}$ when $\mathrm{f}_{\mathrm{si}}=\mathrm{f}_{\mathrm{c}}$. It also can be seen that increasing $\zeta_{\mathrm{c}}$ has no significant effects ${ }^{3}$ on $\mathrm{f}_{\mathrm{os}}$ but increases $\zeta_{o s}$. An extensive discussion of the observed trends in Figure 2 and Figure 3 is presented by Shahabpoor et al. (2013).

To compare the effects of the crowd's parameters $m_{c}, c_{c}, k_{c}$ on the occupied structure's dynamics, a family of initial values is considered in which initial natural frequency of crowd model $\mathrm{f}_{\mathrm{ci}}$ is $3.05 \mathrm{~Hz}$ and structure initial natural frequency $\mathrm{f}_{\mathrm{si}}$ varies from 2 to $4 \mathrm{~Hz}$. For each $\left(\mathrm{f}_{\mathrm{ci}}, \mathrm{f}_{\mathrm{si}}\right)$ pairs, a set of $\mathrm{X}$ vs $\mathrm{Y}$ curves similar to the ones presented in Figure 2 and Figure 3 , are plotted. Maximum absolute value of each of $\mathrm{X}$ vs $\mathrm{Y}$ graphs are then plotted against their corresponding $\mathrm{f}_{\mathrm{ci}} / \mathrm{f}_{\mathrm{si}}$ (which is equal to $3.05 / \mathrm{f}_{\mathrm{si}}$ ) and are presented for $\mathrm{f}_{\mathrm{os}} / \mathrm{f}_{\mathrm{si}}$ and $\zeta_{\mathrm{os}} / \zeta_{\mathrm{si}}$ in Figure 4 and Figure 5 accordingly.

As it can be seen in Figure 4 and Figure 5, as $3.05 / \mathrm{f}_{\mathrm{si}}$ increases, maximum effects of $\mathrm{m}_{\mathrm{c}}$ on $\mathrm{f}_{\mathrm{os}}$ decrease and its effects on $\zeta_{o s}$ increase. $\mathrm{k}_{\mathrm{c}}$ has the opposite effects and as $3.05 / \mathrm{f}_{\mathrm{si}}$ increases, its maximum effects on $f_{o s}$ increase and on $\zeta_{o s}$ decrease. Maximum effects of crowd's damping $c_{c}$ on both $f_{o s}$ and $\zeta_{\text {os }}$ is highest when $\mathrm{f}_{\mathrm{ci}}=\mathrm{f}_{\mathrm{si}}$.

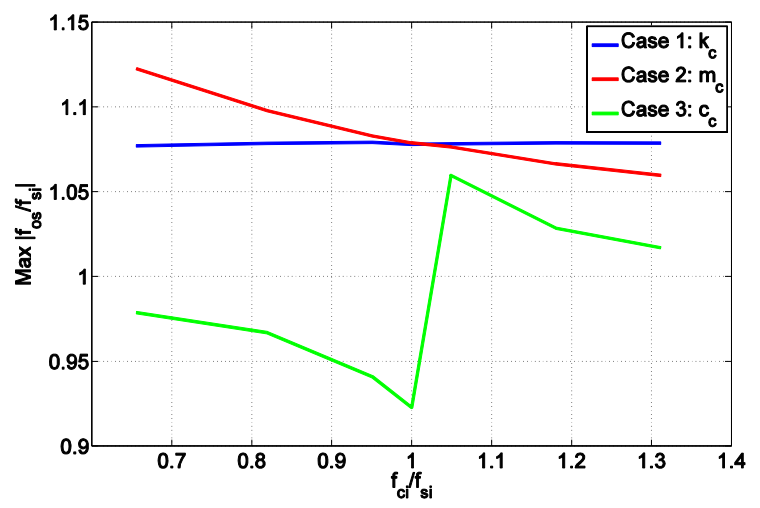

Figure 4: Maximum effects of the $\mathrm{m}_{\mathrm{c}}, \mathrm{k}_{\mathrm{c}}$ and $\mathrm{c}_{\mathrm{c}}$ on $\mathrm{f}_{\mathrm{os}}$ for $\mathrm{f}_{\mathrm{ci}}=$ $3.05 \mathrm{~Hz}$ and $\mathrm{f}_{\mathrm{si}}$ varying from $2-4 \mathrm{~Hz}$

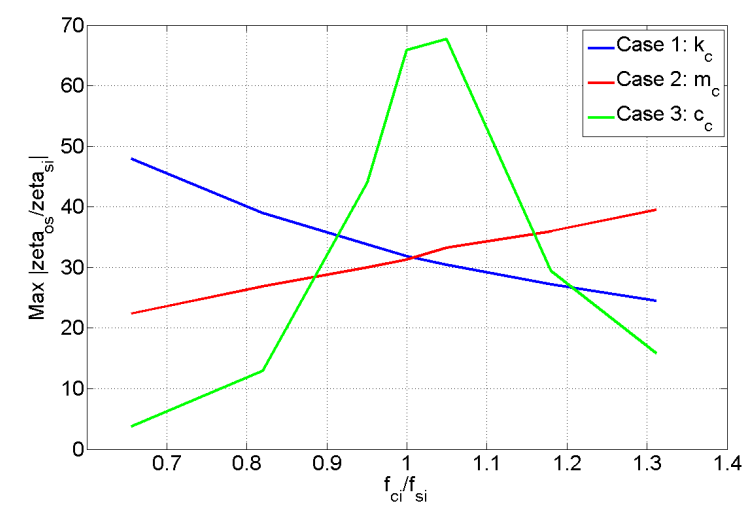

Figure 5: Maximum effects of the $\mathrm{m}_{\mathrm{c}}, \mathrm{k}_{\mathrm{c}}$ and $\mathrm{c}_{\mathrm{c}}$ on $\zeta_{\mathrm{os}}$ for $\mathrm{f}_{\mathrm{ci}}=$ $3.05 \mathrm{~Hz}$ and $\mathrm{f}_{\mathrm{si}}$ varying from $2-4 \mathrm{~Hz}$

\subsection{Sensitivity analysis}

Sensitivity here is defined as the rate of change of $f_{o s}$ and $\zeta_{o s}$ to the changes in $\mathrm{m}_{\mathrm{c}}, \mathrm{k}_{\mathrm{c}}$ and $\mathrm{c}_{\mathrm{c}}$. The sensitivity here is an indicator of 'how fast' the effects of the crowd parameters on the occupied structure parameters change. Results of this section are presented in Figure 6,Figure 7, Figure 8

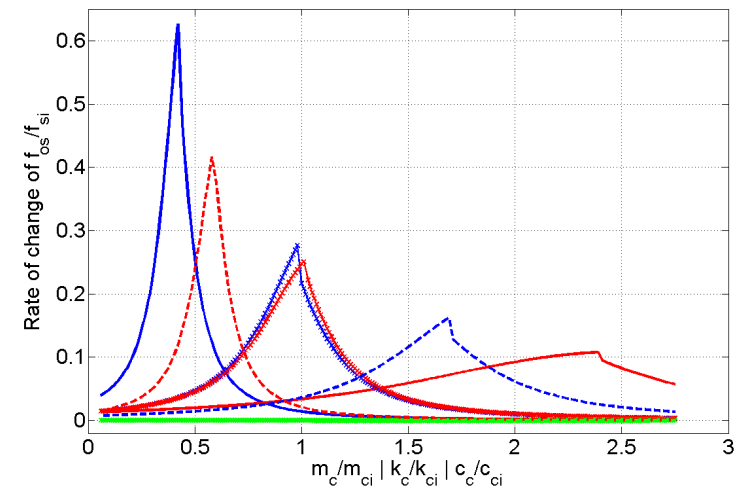

Figure 6: Sensitivity of $\mathrm{f}_{\mathrm{os}}$ to $\mathrm{m}_{\mathrm{c}}$ (red trace), $\mathrm{k}_{\mathrm{c}}$ (blue trace) and $\mathrm{c}_{\mathrm{c}}$ (green trace):

- Continues traces: $\mathrm{f}_{\mathrm{si}}=2 \mathrm{~Hz}$

- Crossed traces: $\mathrm{f}_{\mathrm{si}}=3 \mathrm{~Hz}$

- $\quad$ Dashed line: $\mathrm{f}_{\mathrm{si}}=4 \mathrm{~Hz}$

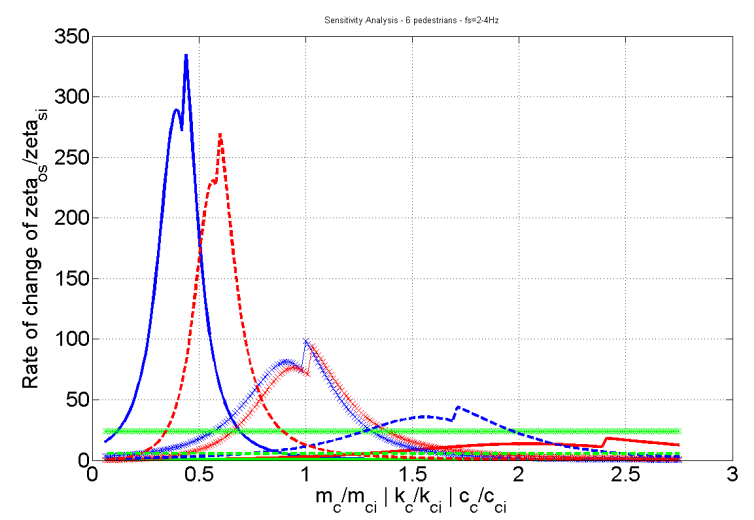

Figure 7: Sensitivity of $\zeta_{\mathrm{os}}$ to $\mathrm{m}_{\mathrm{c}}$ (red trace), $\mathrm{k}_{\mathrm{c}}$ (blue trace) and $\mathrm{c}_{\mathrm{c}}$ (green trace):

- Continues traces: $\mathrm{f}_{\mathrm{si}}=2 \mathrm{~Hz}$

- Crossed traces: $\mathrm{f}_{\mathrm{si}}=3 \mathrm{~Hz}$

- Dashed line: $\mathrm{f}_{\mathrm{si}}=4 \mathrm{~Hz}$
${ }^{3}$ The case presented in Figure 2. Effects of the mc, kc and cc on fos ( $\mathrm{fsi}=4 \mathrm{~Hz}$ ) and Figure 3 is corresponding to the system with proportional damping matrix. In systems with non-proportional damping distribution, natural frequency is dependent on damping but its effects is not significant. Further discussion about details of this issue is beyond the scope of this paper. 
andFigure 9. In these figures, the horizontal axis presents the ratio of the crowd parameters $\mathrm{X}$ as is given in equation 1 and the vertical axis presents derivative of $\mathrm{Y}$ (given in equation 2) with regards to $\mathrm{X}$.

Figure 6 displays the sensitivity of $\zeta_{\text {os }}$ and Figure 7 displays the sensitivity of $\mathrm{f}_{\mathrm{os}}$ for two typical initial structural frequencies $\mathrm{f}_{\mathrm{si}}=2$ and $4 \mathrm{~Hz}$. Similar to the findings in Section 5.1, sensitivity of $\zeta_{o s}$ and $f_{o s}$ to $m_{c}$ and $\mathrm{k}_{\mathrm{c}}$ increase significantly when frequency of the crowd and structure models are close in value.

For the case $f_{c i}<f_{s i}\left(\right.$ when $f_{s i}=4 \mathrm{~Hz}$ ), as both Figure 6 and Figure 7 show, when $k_{c}$ (dashed blue trace) increase from $k_{c i}$ and mass $m_{c}$ (dashed red trace) decrease from $\mathrm{m}_{\mathrm{ci}}$, their corresponding sensitivity curves show a peak. These peaks can be shown to correspond to $f_{s i}=f_{c}$. The same applies when $f_{c i}>f_{s i}\left(\right.$ when $\left.f_{s i}=2 \mathrm{~Hz}\right)$ and the sensitivity curves show maximum when $\mathrm{k}_{\mathrm{c}}$ (blue trace) decrease and $\mathrm{m}_{\mathrm{c}}$ (red trace) increase. Also, as Figure 6 illustrates, rate of change of $f_{o s}$ is not sensitive to $c_{c}$ while sensitivity of $\zeta_{\text {os }}$ is maximum when $\mathrm{f}_{\mathrm{si}}=\mathrm{f}_{\mathrm{ci}}$ (crossed green line in Figure 7).

To compare the sensitivity of $\mathrm{f}_{\mathrm{os}}$ and $\zeta_{\mathrm{os}}$ to $\mathrm{m}_{\mathrm{c}}, \mathrm{k}_{\mathrm{c}}$, and $c_{c}$, the same family of initial values that is described in the previous section is considered in which $\mathrm{f}_{\mathrm{ci}}=3.05 \mathrm{~Hz}$ and $\mathrm{f}_{\mathrm{si}}$ varies from 2 to $4 \mathrm{~Hz}$. For each $\left(\mathrm{f}_{\mathrm{ci}}, \mathrm{f}_{\mathrm{si}}\right)$ pairs, then, a set of $X$ vs $Y^{\prime}$ curves similar to the ones presented in Figure 6 and Figure 7 are plotted. Maximum values of $X v s Y^{\prime}$ graphs are then plotted against teir corresponding $\mathrm{f}_{\mathrm{ci}} / \mathrm{f}_{\mathrm{si}}$ and are presented for $\mathrm{f}_{\mathrm{os}}$ and $\zeta_{\mathrm{os}}$ in Figure 8 and Figure 9 accordingly.

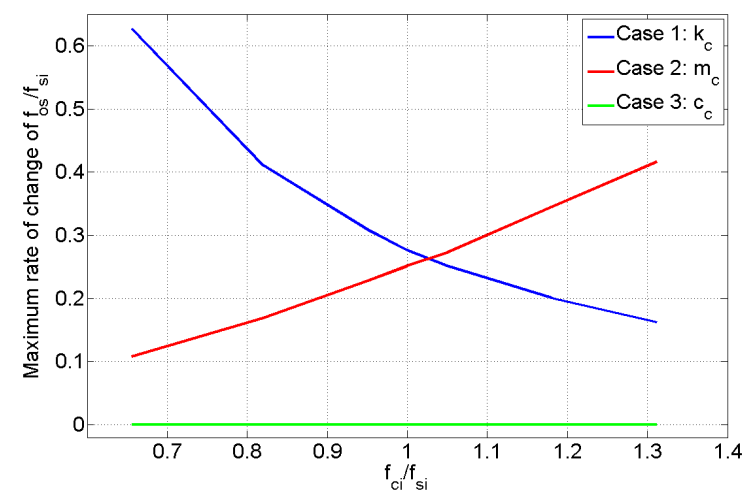

Figure 8: Maximum sensitivity of the $\mathrm{f}_{\mathrm{os}}$ to $\mathrm{m}_{\mathrm{c}}, \mathrm{k}_{\mathrm{c}}$ and $\mathrm{c}_{\mathrm{c}}$ for $\mathrm{f}_{\mathrm{ci}}=$ $3.05 \mathrm{~Hz}$ and $\mathrm{f}_{\mathrm{si}}$ varying from $2-4 \mathrm{~Hz}$

It can be seen in Figure 8 and Figure 9 that by increasing the $f_{s i}$, maximum sensitivity of the $f_{o s}$ and $\zeta_{\text {os }}$ to $\mathrm{k}_{\mathrm{c}}$ decrease (blue traces) and its maximum sensitivity to $\mathrm{m}_{\mathrm{c}}$ increase (red traces). This means that when $\mathrm{f}_{\mathrm{ci}}<\mathrm{f}_{\mathrm{si}}$, both $\mathrm{f}_{\mathrm{os}}$ and $\zeta_{\mathrm{os}}$ are more sensitive to $\mathrm{k}_{\mathrm{c}}$, while when $\mathrm{f}_{\mathrm{ci}}>\mathrm{f}_{\mathrm{si}}$, both $\mathrm{f}_{\mathrm{os}}$ and $\zeta_{\mathrm{os}}$ are more sensitive to $m_{c}$. It also can be seen that $f_{o s}$ has no sensitivity to $\mathrm{c}_{\mathrm{c}}$ while $\zeta_{\mathrm{os}}$ shows a limited sensitivity to $\mathrm{c}_{\mathrm{c}}$ with the maximum at $\mathrm{f}_{\mathrm{ci}}=\mathrm{f}_{\mathrm{si}}$.

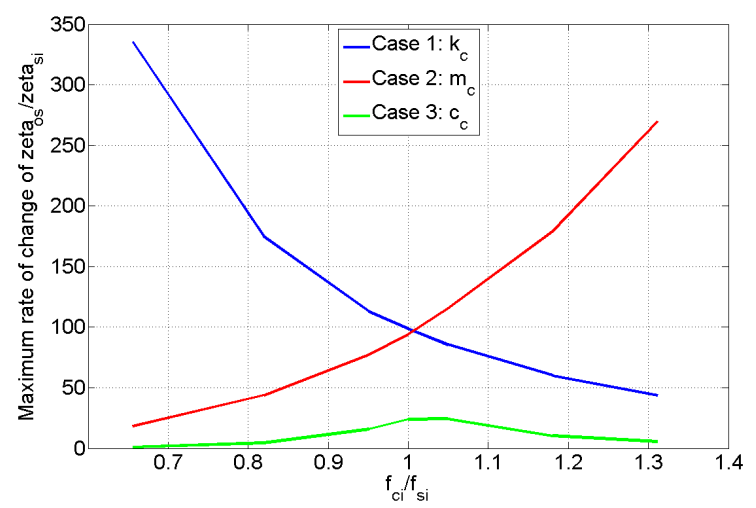

Figure 9: Maximum sensitivity of the $\zeta_{\mathrm{os}}$ to $\mathrm{m}_{\mathrm{c}}, \mathrm{k}_{\mathrm{c}}$ and $\mathrm{c}_{\mathrm{c}}$ for $\mathrm{f}_{\mathrm{ci}}=3.05 \mathrm{~Hz}$ and $\mathrm{f}_{\mathrm{si}}$ varying from $2-4 \mathrm{~Hz}$

\section{CONCLUSION}

Modelling crowd dynamics on structures have always been a challenge due to uncertainty of human parameters. This paper combines results of the parametric study and sensitivity analysis that are done on a 2DOF mass-spring-damper human-structure model to describe effects and sensitivity of the occupied structure to the crowd model parameters $\mathrm{m}_{\mathrm{c}}, \mathrm{k}_{\mathrm{c}}$ and $\mathrm{c}_{\mathrm{c}}$. Results of this analysis provide valuable insight for engineers to choose more realistic crowd properties during design process and researchers to understand better the human-structure interaction mechanisms.

\section{REFERENCES}

Archbold, P., Novel interactive load models for pedestrian footbridges, PhD thesis, University College Dublin,2004.

Archbold, P. 2008. Evaluation of novel interactive load models of crowd loading on footbridges, Proceedings of 4th Symposium on Bridge and Infrastructure Research in Ireland, National University of Ireland, Galway, 35-44.

Archbold, P., Keogh, J. \& Caprani, C. 2011. A Parametric Study of Pedestrian Vertical Force Models for Dynamic Analysis of Footbridges, Proceedings of EVACES 2011.

Bertos, G., Childress, D. \& Gard, S. 2005. The vertical mechanical impedance of the locomotor system during human walking with applications in rehabilitation, Proceeding of the 2005 IEEE Ninth International Conference on Rehabilitation Robotics.

Bocian, M., Macdonald, J. \& Burn, J. 2011. Modelling of selfexcited vertical forces on structures due to walking pedestrians, Proceedings of the 8th International Conference on Structural Dynamics, EURODYN 2011.

Brownjohn, J. M. W., Fok, P., Roche, M. \& Omenzetter, P. 2004. Long span steel pedestrian bridge at Singapore Changi Airport - part 1 and 2.

BSI. 2006. Steel, Concrete and Composite Bridges, Part 2: Specification for Loads; Appendix B: Vibration 
Serviceability Requirements for a Foot and Cycle Track Bridges. BS5400, British Standards Institution.

Caprani, C.C., Keogh, J., Archbold, P. \& Fanning, P. 2011. Characteristic vertical response of a footbridge due to crowd loading, Proceedings of the 8th International Conference on Structural Dynamics, EURODYN 2011.

Dougill, J. W., Wright, J. R., Parkhouse, J. G. \& Harrison, R. E. 2006. Human structure interaction during rhythmic bobbing, The Structural Engineer, 84(22).

Ellis, B. R. \& Ji, T. 1997. Human-structure interaction in vertical vibrations, Structures of Buildings, the Proceedings of Civil Engineers, 122(1), 1-9.

EN. 2004. Eurocode 5: Design of timber structures - Part 2: Bridges, EN 1995-2:2004, European Committee of Standardization.

Geyer, H., Seyfarth, A. and Blickhan, R. 1998. Compliant leg behavior explains basic dynamics of walking and running, Proc. of the Royal Society B: Biological Sciences, 273(1603), pp. 2861-2867.

Kasperski, M. 1996. Actual problems with stand structures due to spectator-induced vibration, Proceedings of Structural Dynamics-EURODYN '96, p 455-461.

Lee, C. \& Farley, C. 1998. Determinants of the center of mass trajectory in human walking and running, The Journal of Experimental Biology, 201, 2935-2944.

Macdonald, J. H. G. 2009. Lateral excitation of bridges by balancing pedestrians, Proc. Royal Society A, 465(2104), pp. 1055-1073.

Matsumoto, Y. \& Griffin, M. 2003. Mathematical models for the apparent masses of standing subjects exposed to vertical whole-body, Journal of Sound and Vibration, 260(3), 431- 451.

Pavic, A. 2011. Vertical crowd dynamic action on footbridges: review of design guidelines and their application, Proceedings of Footbridge Conference 2011.

Rapoport, S., Mizrahi, J., Kimmel, E., Verbitsky, O. \& Isakov, E. 2003. Constant and variable stiffness and damping of the leg joints in human hopping, Journal of Biomechanical Engineering, ASME, 125, 507-514.

Reid, W. M., Dickie, J. F. \& Wright, J. R. 1997. Stadium structures: are they excited. The Structural Engineer, (75), p 383-388.

SCOSS. 2001. Structural Safety 2000-01, 13th Report of the Standing Committee on Structural Safety, p 23-24.

Shahabpoor, E. \& Pavić, A. 2012. Comparative evaluation of current pedestrian traffic models on structures, Conference Proceedings of the Society for Experimental Mechanics Series. V 26, pp 41-52.

Shahabpoor, E., Pavić, A. \& Racic, V. 2013. Using MSD Model to Simulate Human-Structure Interaction during Walking, Conference Proceedings of the Society for Experimental Mechanics Series.

Wei, L. \& Griffin, M. J. 1998. Mathematical models for the apparent mass of the seated human body exposed to vertical vibration, Journal of Sound and Vibration, 212(5), 855-75.

Willford, M. 2002. Dynamic actions and reactions of pedestrians, the proceedings of Footbridges conference.
Zhang, L., Xu, D., Makhsous, M. \& Lin, F. 2000. Stiffness and viscous damping of the human leg, Proceedings of the 24th Annual Meeting of the American Society of Biomechanics.

Živanović, S., Díaz, I. M. \& Pavić, A. 2009. Influence of walking and standing crowds on structural dynamic properties, Proceedings of the IMAC-XXVII.

Živanović, S., Pavić, A. \& Ingólfsson, E. T. 2010. Modelling spatially unrestricted pedestrian traffic on footbridges, ASCE Journal of Structural Engineering, 136(10), pp. 1296-1308. 